\title{
Examining the Effectiveness of Neuro-Linguistic Programming (NLP) techniques in improving Emotional Intelligence (EI) scores
}

\author{
Kamarul Zaman bin Ahmad \\ Dubai Business School, University of Dubai, Dubai, United Arab Emirates, kbinahmad@ud.ac.ae \\ Received: 15 June 2018, revised: 18 March 2019, accepted: 21 March 2019, published: $8^{\text {th }}$ April 2019
}

\begin{abstract}
Since, Ahmad (2011) who looked at the effectiveness of the alternative techniques of NLP, Time Line Therapy ${ }^{\circledR}$, and Hypnosis, there has been no further research regarding the effectiveness of NLP. The purpose of this research is to investigate whether the selected NLP techniques can improve El scores. (Although there are many self-development training courses advertised on the internet claiming to be able to improve El, yet no credible research has been published in peer-reviewed academic journals to show whether such techniques can improve El.). This experimental research involved 35 test subjects and 35 control group subjects. Measurements were taken just before and just after the experiments in the test group and compared the results with the control group. Statistical $t$-tests revealed that with the test group, there were significant improvements in El scores after undergoing the training compared with before. There were no significant changes in the control group. This study improves the study by Ahmad (2011) by ensuring that most of the respondents were not self-selected and ensured the use of other NLP techniques, in the context of improving El.
\end{abstract}

Keywords: Emotional Intelligence, Neuro-Linguistic Programming, Experiments I

\section{INTRODUCTION}

Emotional Intelligence has become a popular topic not only in academic research but also in practice. It is well known for its benefits to organizations and improving the lives of people in general and to stress management in particular. Advertisements relating to self-development training programs are abundant on the internet - as evident from a simple search on Google. NLP has often been touted as a powerful tool for eliciting change and improving the quality of life and happiness. The UAE has made happiness of its citizens and residents its prime objective (Shaikh, \& Ahmad, 2018). Some trainers go as far as to make claims on their websites that their NLP training programs can improve El, but without providing proof in the form of scientific research published in academic peer-reviewed journals. However, there is little or no proof in the form of scientific experiments, whether such techniques are capable of improving El. This research aims to fill that gap. The research question is whether certain NLP techniques are capable of making improvements on El scores of the participants.

\section{LITERATURE REVIEW}

\section{Emotional Intelligence and NLP}

Research on $\mathrm{El}$ is abundant, as are the different ways of operationalizing it. An exhaustive description is not attempted here. Rather, it is pertinent to draw out three theories that are frequently cited. They are the theories of Bar-On (1988, 2006), Mayer and Salovey (1997), and Goleman (1998). Bar-On (1988), in his doctoral dissertation, used the term "emotional quotient" (EQ) and made comparisons with the intelligence quotient (IQ). Bar-On (1997) developed his model which comprises of five main social and emotional abilities - stress management, mood, adaptability, intrapersonal skills, and interpersonal skills. Together these impact a person's 
ability to cope effectively with the demands of the environment. His model places El in the paradigm of personality theories, psychological well-being, and adaptation (Goleman, 1998).

Mayer and Salovey (1997) on the other hand proposed that El comprises of distinct skills which can be improved by training (as opposed to traits which are inherent and fixed). They argued that traditional views of intelligence failed to take into account, the emotional component - that different people have different abilities to perceive, process and effectively manage their emotions. Mayer \& Salovey (1993, pg. 433) defined El is "the ability to monitor one's own and others' emotions, to discriminate among them, and to use the information to guide one's thinking and actions." According to them, El consists of a hierarchy of four levels of abilities from basic emotional perception to more complex cognitive processes.

Goleman (1998) viewed El from the perspective of performance or competencies, and this is what differentiates him from Bar-On (1988) and Mayer and Salovey (1997). According to Goleman (1998), there are five dimensions of emotional intelligence, which are:

1. Self-awareness - being able to know one's emotions, strengths, weaknesses, drives, values, and goals and recognize their impact on others while using gut feelings to guide decisions.

2. Self-regulation - being able to control or redirect one's disruptive emotions and impulses and adapt to changing circumstances.

3. Self-motivation - possesses the drive to achieve for the sake of achievement.

4. Empathy - knows how others feel, especially when making decisions and

5. Social skill - being able to manage relationships to motivate people towards the desired direction

There are two dimensions - personal competence in dealing with oneself, and social competence in dealing with others (Goleman, 1998). We chose Goleman's (1988) model as a framework for the current research because the model has been a popular choice among researchers and is significantly positively correlated with favorable job outcomes. At the same time, we also adopt the theory espoused by Mayor and Salovey (1997) El is a skill that can be improved by training, but without adopting the hierarchical approach used by them. Rather we use the dimensions espoused by Goleman, 1998) and regard that the various dimensions exist on the same level.

\section{What is NLP?}

There are many definitions of NLP. Neuro refers to the nervous system, linguistic refers to not only words but also pictures and sounds, and programming refers to the programs we use to run our minds. NLP is eclectic, in it uses tools that originate from a wide variety of sources (Tosey \& Mathison, 2003; 2010). NLP was founded in 1975 by Richard Bandler, a mathematician and John Grinder, a professor of linguistics (Bandler \& Grinder, 1975; Grinder \& Bandler, 1981). It started when Bandler was asked to transcribe taped audio sessions by Fritz Perlz, a well-known Gestalt therapist. Bandler believed that if he can replicate the methods used by Fritz Perlz, he can also reproduce the outstanding results of Perlz. The basic premise of NLP is modeling which is identifying the specific sequence of thoughts (images, sounds, and feelings) in a person and teaching that structure to another person (Dilts, Grinder, Bandler, Cameron-Bandler, \& DeLozier, 1980). Bandler later teamed up with Grinder to model Virginia Satir (a renowned family therapist) and Milton Erickson (a medical doctor who used hypnosis extensively to treat patients). Together they uncovered techniques which form much of the basis of NLP today. Andreas \& Faulkner (1994) described NLP as a study of human excellence and the "difference that makes a difference." I would describe NLP as a toolbox that contains many tools which can be used in a variety of situations and application. The techniques chosen for this study is described in the methodology section.

\section{El and NLP as stress coping mechanisms}

According to Slaski and Cartwright (2003), El training can improve health and well-being. El has been used widely in healthcare settings (Henwood \& Lister, 2007) as it improves one's ability to cope with stress (Croucher, Sohanpal, Muirhead \& Seymour, 2004). Wei, Ku, Russell, Mallinckrodt, and Liao (2008) examined three coping strategies about stress: reflective, suppressive and reactive. Reflective styles involve planning and thinking ahead. People who practice reflective style can anticipate and prepare for problems before they arise. Among 
the NLP techniques, the value elicitation (finding out the hierarchy of principles or beliefs that are important to oneself) and goal setting exercise are most relevant. The suppressive style of coping involves suppressing the problem, i.e., ignoring the problem or in some extremes denying the existence of the problem. Such behaviors are not congruent with the philosophy of NLP - which is that one must uncover and treat the problem at its source, as soon as it is reasonably possible. Reactive style of coping is having strong emotional responses, impulsivity, and cognitive confusion, basically becoming a victim to the problem, and amplifying the negative emotions. NLP techniques, on the other hand, equip people with tools to handle the emotional challenges when faced with problems.

NLP can also be compared with 'The Ways of Coping Questionnaire' (WCQ: Folkman \& Lazarus, 1988; recently used by Sinha \& Watson, 2007). The WCQ has eight dimensions, namely, confronting coping (aggressively trying to change the stressful situation), distancing, self-controlling, seeking social support, accepting responsibility, escape-avoidance, problem-solving and positive reappraisal. Distancing, and self-controlling, are the philosophy behind the dissociative technique in NLP - one is required to distance oneself (mentally) from the problem, thereby enabling better self-control. Positive reappraisal and accepting responsibility are the vital prerequisites that must exist before beginning the value elicitation and goal setting exercises in NLP. Social support and NLP rapport are related to one another - to render support to others effectively, one must first know how to establish rapport. Thus, that NLP techniques can be used as tools to implement the principles behind the WEQ, thereby enabling one to handle stress better. Since El is negatively related to stress, and NLP techniques can help one to cope with stress, then it would also be reasonable to propose that NLP techniques can help improve El. The next task will be to select the relevant technique(s) in NLP to improve the relevant dimension of El.

\section{NLP techniques which can improve EI}

NLP has many techniques designed to improve self-confidence and well-being. The following El dimensions as per Goleman (1998) are listed below and beside each dimension, the most appropriate NLP techniques (indicated in parentheses), are identified:

i) Self-Awareness (values hierarchy and goal setting)

ii) self-regulation (dissociative technique)

iii) self-motivation (associative technique)

iv) empathy (matching and mirroring)

v) social skills (rapport)

The NLP techniques are described in more detail under the heading of instructions and the reasons for their selection will become obvious from reading the descriptions.

\section{Justification for more research in NLP}

There is a dearth of academic research on NLP, with virtually no recent publication supporting its effectiveness (Tosey \& Mathison, 2003), until the study by Ahmad (2011). On the contrary, previous studies from the 1980s and early 1990s attempted to debunk NLP as pseudoscience and ineffective (Dorn, Brunson, \& Atwater, 1983; Poffel \& Cross, 1985; Baddeley \& Predebon, 1991). In particular, Heap (1988) and Sharpley (1984) conducted several studies to debunk the notion of 'primary representational system,' put forward by Grinder \& Bandler (1976) where individuals have a preferred sensory mode (visual, auditory or kinesthetic) and responded favourably when others use the same mode as them. Results of the experiments showed that there were no differences in outcomes between the test groups and the control groups, leading Heap (1988) and Sharpley (1984) to conclude that NLP techniques do not work as claimed. However, Einspruch and Forman (1985) defended NLP and instead, attacked previous research stating that such 'failed' research (as many as thirtynine separate experimental studies) had critical flaws such as using researchers who are not properly trained and certified in NLP. One of the studies mentioned was Dowd and Hingst's (1983), where students who were not familiar with NLP were trained in four 90-min sessions before administering the experiments. In contrast, a person would have to have to undergo approximately 130 hours of training and pass tests (both written and practical) to be certified at the Practitioner level (and more if he/she were to proceed to the Masters and Trainers level). Furthermore, previous researchers failed to realize the interdependence of the different NLP techniques. 
Just as learning one topic in Management does not make one a manager, learning one NLP topic or technique in isolation does not render one proficient in NLP. There are other skills which are necessary as a prerequisite, such as establishing rapport. Rapport is not just about merely matching representational systems (e.g., visual, auditory or kinesthetic), as was done in previous "failed" studies. It is much more complex requiring one to match and mirror many other aspects such as voice qualities (volume, tonality, speed) and even body posture, facial expressions, and breathing. Einspruch and Forman (1985) pointed out that researchers in many previous studies such as Hammer (1983), Dorn (1983), Ehrmantraut (1983), Appel (1983), Cody (1983), Dowd and Pety (1982), Ellickson (1981; 1983), Brockman (1981), Falzett (1981), Green (1981), and Paxton (1981), may have failed to obtain the submission and cooperation of the respondent - a critical ingredient for NLP to work. Einspruch and Forman (1985) asserted that if comparisons are to be made with other clinical approaches, the administrators conducting the experiments in NLP must have the necessary qualifications as proof of proficiency. It is insufficient to simply attend one or two workshops, read a book and assume that one can effectively perform NLP therapy, any more than this can be assumed for any other model of therapy. In contrast, the researcher in the current study is certified by the American Board of NLP as a trainer for several years.

Despite the huge effort by Einspruch and Forman (1985) to defend NLP, they have failed to conduct any experiments to validate any of the NLP techniques. This daunting task was taken up by Ahmad (2011) who looked at the effectiveness of the alternative techniques of NLP, Time Line Therapy®, and Hypnosis as means of reducing the intensity of negative emotions associated with memories of stressful events from the past. Ahmad (2012) conducted experimental scientific research that involved 32 test subjects and 32 control group subjects. Statistical t-tests revealed that for the test group there were significant reductions in intensity levels of negative emotions after undergoing the procedures compared with before, for all three methods. In contrast, there were no significant changes in the control group. This is the most recent research publications (if not the only one) about the effectiveness of the NLP dissociative technique. However, closer inspection revealed two limitations of the study: firstly, most of the respondents were self-selected, and secondly, other NLP techniques were not examined. The current study avoids both these limitations.

From the literature review above, the following hypotheses were developed:

\section{H1: The NLP techniques of values hierarchy and goal setting can improve the self-awareness dimension of El.}

H2: The NLP dissociative techniques can improve the self-regulation dimension of El.

\section{H3: The NLP associative technique can improve the self-motivation dimension of El.}

H4: The NLP techniques of matching and mirroring can improve the empathy dimension of El.

\section{H5: The NLP rapport technique can improve the social skills dimension of El.}

More detailed description of the selected NLP techniques is given in the methodology section below.

\section{METHODS}

\section{The measures}

There are a variety of multi-item measures of $\mathrm{El}$, and the authors of each version will claim that their questionnaire is superior compared with others. Closer examination of the questionnaires revealed that there could be potential problems such as length and meaning for the respondents. The researcher adopted a simpler approach by focusing on the face validity of the questions. Each El dimension was measured by using the definition of the dimension itself, using only one item for each dimension. Previous studies have shown that one-item measures can be strongly correlated with more complex multidimensional measures (Ahmad, 2001). Consequently, the items are as follows:

1) Self-awareness was measured by a one-item question as follows: "I am aware of myself as a person regarding my character, strengths, weakness, drives values and goals, and how they impact others."

2) Self-regulation question: "I can control or redirect disruptive emotions and impulses while adapting to changing circumstances." 
3) Self-motivation question: "I know how to, and can motivate myself to achieve for the sake of achievement."

4) Empathy question: "I can know how others are feeling, especially when making decisions."

5) Social skill question: "I can manage my relationships with others and to move people in the desired direction."

These items were scored on 5-point Likert scales ranging from strongly disagree (1) to strongly agree (5). For each question, there were two columns for participants to fill in. A research assistant distributed the questionnaires to all participants before the training. Participants filled the questionnaires before, as well as immediately after, the training session. The research assistant collected the questionnaires after the end of the session. This enabled accurate analyses of "before and after" scores for each respondent. Although the researcher played the role of both facilitator and researcher, objective scoring was used to minimize researcher bias, and no data was collected by the researcher's observation. Respondents filled in the self-administered questionnaires and a research assistant entered the scores directly into the Statistical Package for Social Sciences (SPSS), without any transformation whatsoever by the researcher. The research assistant distributed the questionnaires in the absence of the researcher to reduce the demands effect.

The respondents in the control group also filled out the questionnaire twice. The period between filling-up the questionnaires was two and a half hours which is approximately how long the test group took to do the activities. The control group was not taught any NLP techniques during this period. Instead, they were taught a lesson on SPSS - an emotionally neutral subject.

This research was conducted in a country where no prior ethics approval was required for such a study. The participants verbally consented to participate in this research at the beginning of the training and subsequently filled out all the questionnaires.

\section{The sample}

Respondents in the test group totaled 35 participants. The training session was conducted personally by the researcher. Respondents were selected using the random assignment as follows: the researcher first prepared a sampling frame from the list of classes in postgraduate business studies taught by the researcher at a University. One of the conditions was that the class must have the maximum number of 35 students. One class was treated as the test group, and the other class was treated as a control group. This ensured that the test group is comparable (although not exactly identical) with that of the subject group (Zikmund, Babin, Carr \& Griffin, 2010) since both are graduate classes of business at the same university. The sample consists of 35 participants in the test group and 35 participants in the control group.

The control group has roughly the same mean age as the test group, which is 38 years. The age range in the control group was 28-47 years, but the age range in the test group was 26-45 years. There are only slight differences regarding gender composition - 17 males and 18 females in the test groups and also 19 males and 16 females in the control group. In terms of number of subjects in test groups and control groups, this research is superior to others (22 test groups and 22 control groups in Shakibaei, Harandi, Gholamrezaei, Samoei, \& Salehi, 2008; eight female patients and no control group in Keefer \& Keshavarzian, 2007; and one test person and no control group in Ewin, 2004).

\section{Instructions}

\section{The value hierarchy and goal setting (in conjunction with El dimension of self-awareness)}

The researcher asked the respondents to list what values are important for them and then rank these values. The respondents received coaching, guidance, and individual assistance from the researchers during the session. The researcher trained them how to formulate "SMART" goals, but with finer distinctions in line with the NLP philosophy. For example, goals have to be positively stated, i.e., what they want (as opposed to the negative, i.e., what they don't want) and expressed in the present tense (and not past or future tense). 


\section{Dissociative technique (in conjunction with El dimensions of self-regulation)}

Respondents were asked to remember an event that they still felt stressed about. Then, the researcher taught them the dissociative technique used by Ahmad (2011). This procedure required them to see the event through the third person view, and then change the 'submodalities' of the mental picture by changing it from color to black and white, reduce the clarity and size and gradually push the picture further away.

\section{Associative technique (in conjunction with El dimension of self-motivation)}

Respondents were asked to choose one task or activity that they want to feel more motivated about. Then they did the opposite of what they had done earlier, i.e., they were asked to imagine the task vividly and associate themselves into the memory, i.e., see the event through the first person view (looking through their own eyes and not seeing their body in the picture). Then, they were asked to change the 'submodalities' of the mental picture by increasing the color, brightness, clarity, and size and gradually bringing the picture closer towards them.

\section{Matching and mirroring technique (in conjunction with El dimensions of empathy)}

Respondents first learned how to match and mirror the body posture and facial expressions of others. Matching simply means that one is imitating the body posture, facial expressions and voice qualities of others. The difference between matching and mirroring is, in matching, if one person has his/her right arm raised, the other person also raises the right arm. In mirroring, if the person has his/her right arm raised, the person opposite raises the left arm.

Respondents were told to assemble in groups of three. In each group, one person plays the role of the one being observed, and the other, the person who matches and mirrors. The third person plays the role of thirdparty observer, who observes the other two, and makes fine adjustments to the matcher/mirror so that he/she exactly matches/mirrors the observed. The person who matches/ mirrors, then have to deduce what the person being observed, is thinking and feeling.

\section{Rapport (in conjunction with social skills)}

For this exercise, respondents were taught not only how to match and mirror the body posture and facial expressions of others, but also their voice qualities (volume, pitch, tempo, timbre and keywords). Researchers divided the respondents into two groups, and in both groups, participants were asked to form pairs. In the first group, one person talks while the other listens and deliberately does not match and mirror. For the second group, one person talks while the other listens and matches or mirrors the other. This procedure went on for five minutes. For both groups, the instructor then asks the respondent who was doing the talking whether they felt connected with the listeners. Respondents reported verbally that connection or rapport exists much more in groups where the listener matches or mirrors the talker, compared with groups where the listener does not.

\section{ANALYSIS AND RESULTS}

Paired samples T-Test were conducted, and results showed that there were significant increases in the mean values of the EI scores after the NLP activities, compared with before. Overall, the NLP techniques chosen for this study managed to increase the El scores for each dimension, thus improving the total El scores of the test subjects. In contrast, the control group had no changes in El scores.

Table 1: Mean scores of the test group of respondents before and after the NLP training

\begin{tabular}{|l|l|l|l|l|}
\hline $\begin{array}{l}\text { EI } \\
\text { dimension }\end{array}$ & NLP technique & $\begin{array}{l}\text { Mean scores before } \\
\text { NLP activity }\end{array}$ & $\begin{array}{l}\text { Mean scores before } \\
\text { NLP activity }\end{array}$ & Significance \\
\hline $\begin{array}{l}\text { self- } \\
\text { awareness }\end{array}$ & $\begin{array}{l}\text { values hierarchy and } \\
\text { goal setting }\end{array}$ & 4.8 & 6.5 & Sig \\
\hline $\begin{array}{l}\text { self- } \\
\text { regulation }\end{array}$ & dissociative technique & 4.7 & 7.6 & Sig \\
\hline
\end{tabular}




\begin{tabular}{|l|l|l|l|l|}
\hline $\begin{array}{l}\text { self- } \\
\text { motivation }\end{array}$ & associative technique & 4.8 & 7.6 & Sig \\
\hline empathy & matching and mirroring & 4.9 & 5.7 & Sig \\
\hline social skills & rapport & 4.9 & 6.8 & Sig \\
\hline
\end{tabular}

\section{CONCLUSIONS}

This study examined the effectiveness of selected NLP techniques as means of improving El scores. The sample consisted of 35 individuals in the test groups and 35 individuals in the control group. Measurements were taken before and after each of the procedures. Overall, the NLP techniques chosen for this study managed to increase the El scores for each dimension, thus improving the total El scores of the test subjects. In contrast, the control group had no changes in El scores. The difference in outcomes between the test and control groups suggests that the selected NLP techniques are effective and are responsible for these changes.

Some respondents reported more favorable experiences with some of the techniques compared with others. Among the favorites are the associative and dissociative techniques used to improve the self-motivation and self-regulation dimensions of El, respectively - respondents enjoyed being able to take charge of their emotions. The least favorite technique was the NLP matching and mirroring which was used to improve the empathy dimension. Some groups reported outstanding success with such techniques and reported high scores after the techniques. But many groups were unable to read others' emotions using this technique, resulting in a lack of confidence in this technique and therefore reported lower scores. The values hierarchy was popular among participants (according to their verbal reports), but because that technique was taught together with goal setting techniques (which many are already familiar with), the overall increase in scores was less compared with the associative and dissociative techniques.

In the current study, the final sample consisted of students in a randomly picked class. Although the researcher conducted the experiments, the data collected in this research was not through the researcher's observations (which could potentially introduce bias and is thus objectionable) but thru self-administered questionnaires with objective scoring. Thus, it has no more bias than self-administered surveys. Objective scoring per se (unlike data collection by observation) introduces no bias because the scores would be the same if another person compiled it. It is worth pointing out that in this study, a research assistant distributed, collected and compiled the questionnaires. Demand effects are reduced by not telling the respondents of the purpose of the experiments (i.e., whether NLP techniques can improve El) but just simply teach them the techniques.

However, there is still a limitation in this study in that there is no way of knowing whether the increases in $\mathrm{El}$ scores are permanent or temporary. Future research could take the form of a longitudinal study spread over a year and measurements can be taken in one, three, six months, and one year into the future. However, longitudinal studies are still inconclusive as it is difficult to control all the extraneous variables that exist in a field setting, such as traumatic life-changing events and whether the test subjects continue to practice the NLP techniques. This is something that exists in other experimental studies such as Ewin, 2004; Keefer \& Keshavarzian, 2007; Shakibaei, Harandi, Gholamrezaei, Samoei, \& Salehi, 2008. Lastly, data were obtained through self-report instruments. The limitations that apply to self-report questionnaires, such as self-serving bias, have the potential to be present in this research, just as it has the potential to be present in all other research using self-report measures.

\section{REFERENCES}

Ahmad, K. Z. (2001). The Association between Person, Work Environment, Job Satisfaction and Performance: A study in light manufacturing assembly plants. Unpublished PhD thesis, University of Manchester Library.

Ahmad, K. Z. (2011). Alternatives to simply forgiving and forgetting: examining techniques in hypnosis, NLP and Time Line Therapy in reducing the intensity of negative emotions attached to memories of stressful events. Stress and Health, 27(3), 241-250.

Andreas, S., \& Faulkner, C. (1994). NLP - The New Technology of Achievement. New York: William Morrow.

Appel, P. (1983). Matching representational systems and interpersonal attraction. United States International University, Dissertation Abstracts International 43, 3021B: (University Microfilms No 83-018, 35). 
Baddeley, M., \& Predebon, J. (1991). 'Do the eyes have it?': A test of neurolinguistic programming's eye-movement hypothesis. Australian Journal of Clinical Hypnotherapy and Hypnosis, 12(1), 1-23.

Bandler, R., \& Grinder, J. (1975). The structure of magic I: A book about language and therapy. Palo Alto, CA: Science and Behaviour Books.

Bar-On, R. (1988). The development of a concept of psychological well-being. Unpublished doctoral dissertation, Rhodes University: South Africa.

Bar-On, R. (1997). The Emotional Quotient Inventory (EQ-I): a test of emotional intelligence. Toronto: Multi-Health Systems.

Bar-On, R. (2006). The Bar-On model of emotional-social intelligence (ESI). Psicothema, 18, supl., 13-25.

Brockman, W. (1981). Empathy revisited: The effect of representational system matching on certain counselling process and outcome variables. (Doctoral dissertation, College of William and Mary). Dissertation Abstracts International, 41 , 3421A: (University Microfilms No. 81-035, 91).

Cody, S. G. (1983). The stability and impact of the primary representational system in Neurolinguistic Programming: A critical examination. (Doctoral dissertation, University of Connecticut). Dissertation Abstracts International, 44, 1232B: (University microfilms No. 83-191, 87).

Croucher, R., Sohanpal, R., Muirhead, V., \& Seymour, K. (2004). Emotional intelligence and stress coping in dental undergraduates - a qualitative study. British Dental Journal, 197, 205-209.

Dilts, R., Grinder, J., Bandler, R., \& Delozier, J. (1980). Neuro-linguistic programming (Vol. 1), The study of the structure of subjective experience. Capitola, CA: Meta Publications.

Dorn, F. J. (1983). The effects of counsellor-client predicate use in counsellor attractiveness. American Mental Health Counselor's Association Journal, 5, 22-30.

Dorn, F. J., Brunson, B. I., \& Atwater, M. (1983). Assessment of primary representational systems with neuro-linguistic programming: examination of preliminary literature. American Mental Health Counsellors Journal, 5(4), 161-168.

Dowd, E., \& Hingst, A. (1983). Matching therapists' predicates: An in vivo test of effectiveness. Perceptual and Motor Skills, $57,207-210$.

Dowd, E., \& Petty, J. (1982). Effect of counsellor predicate matching on perceived social influence and client satisfaction. Journal of Counseling Psychology, 29, 206-209.

Ehrmantraut, J. E. (1983). A comparison of the therapeutic relationship of counselling students trained in neurolinguistic programming vs students trained in the Carkuff model. (Doctoral dissertation Abstracts International, 44, 3191B): (University Microfilms No. 83-284,91).

Einspruch, E. L., \& Forman, B. D. (1985). Observations concerning research literature on Neuro Linguistic Programming. Journal of Consulting Psychology, 32(4), 589-596.

Ellickson, J. (1981). The effect of interviewers responding differentially to participants' eye movement. (Dissertation Abstracts International, 41, 2754B). (University Microfilms No.81-01,102).

Ellickson, J. (1983). Representational systems and eye movements in an interview. Journal of Counseling Psychology, 30 , 339-345.

Ewin, D. M. (2004). Single-visit hypnotic cure of stentorian snoring: a brief communication. International Journal of Clinical and Experimental Hypnosis, 52(4), 400-403.

Falzett, W. (1981). Matched versus unmatched primary representational systems and their relationship to perceived trustworthiness in a counselling analog. Journal of Counseling Psychology, 28, 305-308.

Folkman, S., \& Lazarus, R. S. (1988). Manual for the Ways of Coping Questionnaire: Research edition. Palo Alto, CA: Consulting Psychologists Press.

Goleman, D. (1998). Working with emotional intelligence. New York: Bantam Books.

Goleman, D. (1998). Working with Emotional Intelligence. Bantam Books.

Green, M. (1981). Trust as affected by representational system predicates. (Doctoral dissertation, Ball State University, 1979). Dissertation Abstracts International, 41, 3159B-3160B: (University Microfilms No. 81-046, 51).

Grinder, J., \& Bandler, R. (1976). Patterns of the Hypnotic Techniques of Milton H. Erickson, M.D. Volume I. Cupertino, CA: Meta Publications.

Grinder, J., \& Bandler, R. (1981). Trance-formations. Moab, UT: Real People Press.

Hammer, A. (1983). Matching perceptual predicates: Effect on perceived empathy in a counselling analog. Journal of Counseling Psychology, 30, 172-179.

Heap, M. (1988). Neurolinguistic programming - an interim verdict. In M. Heap (Ed.), Hypnosis: Current clinical, experimental and forensic practices (pp. 268-280). London: Croom Helm.

Henwood, S., \& Lister, J. (2007). NLP and Coaching for Health Care Professionals: Developing Expert Practice. Chichester, West Sussex, England: John Wiley \& Sons Ltd.

Keefer, L., \& Keshavarzian, A. (2007). Feasibility and acceptability of gut directed hypnosis on inflamatory bowel disease: A brief communication. International Journal of Clinical and Experimental Hypnosis, 55(4), 457-466. 
Mayer, J. D., \& Salovey, P. (1993). The intelligence of emotional intelligence. Intelligence, 17(4), 433-442.

Mayer, J. D., \& Salovey, P. (1997). What is emotional intelligence? In P. Salovey, \& D. Sluyter (Eds.), Emotional development and emotional intelligence: implications for educators (pp. 3-31). New York: Basic Books.

Paxton, L. (1981). Representational systems and client perception of the counselling relationship. (Doctoral dissertation, Indiana University, 1980). Dissertation Abstracts International, 41, 3888A: (University Microfilms No. 81-059, 41).

Poffel, S. A., \& Cross, H. J. (1985). Neurolinguistic programming: A test of the eye-movement hypothesis. Perceptual and Motor Skills, 61(3), 12-62.

Shaikh, M. W. \& Ahmad, K. Z. B. (2018). Factors affecting Happiness of Expatriate Academicians and Expatriate NonAcademicians in Dubai, a comparative study. International Review of Advances in Business Management and Law, 1(1). ISSN 2616-4272. Available online at http://publications.ud.ac.ae/index.php/IRBML

Shakibaei, F., Harandi, A. A., Gholamrezaei, A., Samoei, R., \& Salehi, P. (2008). Hypnotherapy in management of pain and reexperiencing trauma in burn patients. International Journal of Clinical and Experimental Hypnosis, 56(2), $185-197$.

Sharpley, C. (1984). Predicate matching in NLP: A review of research on the preferred representational system. Journal of Counseling Psychology, 31, 238-248.

Sinha, B. K., \& Watson, D. C. (2007). Stress, coping and psychological illness: a cross cultural study. International Journal of Stress Management, 14(4), 386-397.

Slaski, M., \& Cartwright, S. (2003). Emotional intelligence training and its implications for stress, health and performance. Stress and Health, 19(4), 233-239.

Tosey, P., \& Mathison, J. (2003). Neuro-linguistic programming and learning theory: A response. The Curriculum Journal, 14(3), 361-378.

Tosey, P., \& Mathison, J. (2010). Neuro-Linguistic programing as an innovation in education and teaching. Innovations in Education and Teaching International, 47(3), 317-326.

Wei, M., Ku, T. Y., Russell, D. W., Mallinckrodt, B., \& Liao, K. Y. (2008). Moderating effects of three coping strategies and self-esteem on perceived discrimination and depressive symptoms: A mnoirty stress model for Asian international students. Journal of Counseling Psychology, 55(4), 451-462.

Zikmund, W. G., Babin, B. J., Carr, J. C., \& Griffin, M. (2010). Business Research Methods (8th ed.). South-Western: Cengage Learning. 